\title{
Study of the Comparative Effect of Sintering Methods and Sintering Additives on the Microstructure and Performance of $\mathrm{Si}_{3} \mathrm{~N}_{4}$ Ceramic
}

\author{
Liangliang Yang ${ }^{1}$, Allah Ditta ${ }^{1}$, Bo Feng ${ }^{1}$, Yue Zhang ${ }^{1, *}$ and Zhipeng Xie ${ }^{2}$ \\ 1 School of Materials Science and Engineering, Beihang University, Beijing 100191, China \\ 2 State Key Laboratory of New Ceramics and Fine Processing, School of Materials Science and Engineering, \\ Tsinghua University, Beijing 100084, China \\ * Correspondence: zhangy@buaa.edu.cn; Tel.: +86-010-8231-6976
}

Received: 12 June 2019; Accepted: 1 July 2019; Published: 3 July 2019

\begin{abstract}
The $\mathrm{Si}_{3} \mathrm{~N}_{4}$ ceramics were prepared in this study by gas pressure sintering (GPS) and spark plasma sintering (SPS) techniques, using $5 \mathrm{wt} . \% \mathrm{Yb}_{2} \mathrm{O}_{3}-2$ wt. $\% \mathrm{Al}_{2} \mathrm{O}_{3}$ and 5 wt. $\% \mathrm{CeO}_{2}-2$ wt. $\%$ $\mathrm{Al}_{2} \mathrm{O}_{3}$ as sintering additives. Based on the difference in sintering methods and sintering additive systems, the relative density, phase composition, phase transition rate, microstructure, mechanical properties, and thermal conductivity were comparatively investigated and analyzed. SPS proved to be more efficient than GPS, producing higher relative density, bending strength, hardness, and thermal conductivity of $\mathrm{Si}_{3} \mathrm{~N}_{4}$ ceramic with both additive systems; however, the phase transition rate and fracture toughness were lower. Similarly, higher bending strength, hardness, and thermal conductivity were achieved with $\mathrm{Yb}_{2} \mathrm{O}_{3}-\mathrm{Al}_{2} \mathrm{O}_{3}$ than $\mathrm{CeO}_{2}-\mathrm{Al}_{2} \mathrm{O}_{3}$ in the case of GPS and SPS, and only the relative density, fracture toughness, and phase transition rate were lower.
\end{abstract}

Keywords: GPS; SPS; microstructure; mechanical performance; sintering additives; silicon nitride

\section{Introduction}

Silicon nitride is an attractive structural material with high-temperature strength, good hardness, and excellent wear and corrosion resistance, and it has wide applications in the high-temperature structural material field, such as for cutting tools, bearings, high-pressure plugs, and sealing rings.

The research on silicon nitride mainly consists of the following: rational selection of sintering aids, sintering techniques and control of technological parameters, manipulation of microstructure (such as grain boundary phase, grain boundary thickness, grain size, crystal phase transition rate from $\alpha-\mathrm{Si}_{3} \mathrm{~N}_{4}$ to $\beta-\mathrm{Si}_{3} \mathrm{~N}_{4}$, etc.) to accordingly adjust the mechanical and thermal properties. Silicon nitride has a strong covalent bond structure. Therefore, the diffusion coefficient is low, and the sintering driving force is weak. It is challenging to densify silicon nitride without sintering aids; thus, choosing a suitable additive for densification is a crucial step. The selection criteria while sintering for sintering aids, in general, are as follows: (1) capable of forming liquid phase to promote densification and crystal phase transition from $\alpha-\mathrm{Si}_{3} \mathrm{~N}_{4}$ to $\beta-\mathrm{Si}_{3} \mathrm{~N}_{4}$ by solution reprecipitation; (2) full or partial crystallization of the liquid phase upon cooling to reduce the proportion of glassy phase at grain boundaries; (3) enough high-temperature strength of grain boundary phase [1]. At present, the usual additives are $\mathrm{Y}_{2} \mathrm{O}_{3}-\mathrm{Al}_{2} \mathrm{O}_{3}, \mathrm{Y}_{2} \mathrm{O}_{3}-\mathrm{Nd}_{2} \mathrm{O}_{3}$, and $\mathrm{MgO}-\mathrm{SiO}_{2}$ [2-5] for liquid phase formation and good densification. However, the crystallization of the second phase at grain boundaries is incomplete. In recent years, researchers began to notice $\mathrm{Yb}_{2} \mathrm{O}_{3}$ as a preferable sintering additive because $\mathrm{Yb}_{2} \mathrm{O}_{3}$ not only has a similar sintering effect to $\mathrm{Y}_{2} \mathrm{O}_{3}$, but the bending strength of the silicon nitride with $\mathrm{Yb}_{2} \mathrm{O}_{3}$ is also better than that of $\mathrm{Y}_{2} \mathrm{O}_{3}[6,7]$. 
Kondo et al. [8,9] added $13 \mathrm{wt} . \% \mathrm{Yb}_{2} \mathrm{O}_{3}$ into silicon nitride and obtained superior mechanical properties at room and high temperature $(1773 \mathrm{~K})$. Vetrano et al. $[10,11]$ systematically investigated the influence of $\mathrm{Yb}_{2} \mathrm{O}_{3}$ content on mechanical properties for silicon nitride and found that, when the content of $\mathrm{Yb}_{2} \mathrm{O}_{3}$ was higher than $5 \mathrm{wt}$.\%, it significantly improved the crystallization of grain boundary phases and, consequently, material strength. Research on $\mathrm{CeO}_{2}$ also established it as an effective additive which promotes liquid phase sintering at lower temperature, while remarkably increasing the bending strength and hardness of silicon nitride [12,13]. Other documents reported that $\mathrm{Al}_{2} \mathrm{O}_{3}$ can promote the mechanical properties of silicon nitride ceramics $[14,15]$. Thus, we infer that it can densify $\mathrm{Si}_{3} \mathrm{~N}_{4}$ ceramics with the addition of $\mathrm{Yb}_{2} \mathrm{O}_{3}-\mathrm{Al}_{2} \mathrm{O}_{3}$ or $\mathrm{CeO}_{2}-\mathrm{Al}_{2} \mathrm{O}_{3}$, and such ceramics should have high thermal conductivity and excellent high-temperature mechanical properties.

The industries mainly adopt gas pressure sintering (GPS) for silicon nitride as it is an economical method; however, the technique normally consists of a prolonged heating cycle. On the other hand, many research institutes apply the spark plasma sintering (SPS) technique because it is a relatively new sintering technique that can rapidly densify ceramic powders at lower temperatures; however, this equipment is expensive. Thus, how to strike a good balance between the ceramic performance and the cost is a critical issue. Furthermore, the comparative effects of sintering additives $\mathrm{Yb}_{2} \mathrm{O}_{3}-\mathrm{Al}_{2} \mathrm{O}_{3}$ and $\mathrm{CeO}_{2}-\mathrm{Al}_{2} \mathrm{O}_{3}$ using GPS and SPS sintering techniques are less studied for silicon nitride. In this work, we used 5 wt. $\% \mathrm{Yb}_{2} \mathrm{O}_{3}-2$ wt. $\% \mathrm{Al}_{2} \mathrm{O}_{3}$ and 5 wt. $\% \mathrm{CeO}_{2}-2$ wt. $\% \mathrm{Al}_{2} \mathrm{O}_{3}$ as sintering additives and employed GPS and SPS to prepare silicon nitride ceramics. The aim was to comparatively study the influence of sintering techniques and sintering additives on the structure and performance of silicon nitride. The effects on phase transformation, grain boundary phase, bending strength, hardness, fracture toughness, microstructure, and thermal conductivity of the ceramics were investigated.

\section{Experimental Procedure}

\subsection{Raw Material and Preparation of Samples}

Commercial $\mathrm{Si}_{3} \mathrm{~N}_{4}$ powder (average size of $\sim 0.1 \mu \mathrm{m}$, purity $\geq 99 \%, \alpha$ phase content $\geq 95 \mathrm{wt} . \%$, dissociated $\mathrm{Si} \leq 0.3 \mathrm{wt} . \%, \mathrm{Fe} \leq 0.25 \mathrm{wt} . \%$, Jinsheng Ceramics Co., Ltd., Changzhou, China) and additives $\mathrm{Yb}_{2} \mathrm{O}_{3}, \mathrm{CeO}_{2}$, and $\mathrm{Al}_{2} \mathrm{O}_{3}$ (analytical grade) (Guoyao, Beijing, China) were used as the starting materials. The samples with an additive combination of $\mathrm{Yb}_{2} \mathrm{O}_{3}-\mathrm{Al}_{2} \mathrm{O}_{3}$ and $\mathrm{CeO}_{2}-\mathrm{Al}_{2} \mathrm{O}_{3}$ were named $\mathrm{YA}$ and $\mathrm{CA}$, respectively, while, to identify the sintering technique, prefixes $S$ and $G$ were defined before $Y A$ and $C A$ to represent SPS and GPS, respectively. The powders were mixed in ethanol (Guoyao, Beijing, China) in accordance with Table 1, ball-milled for $20 \mathrm{~h}(\mathrm{~h})$, vacuum-dried, and subsequently sieved $(75 \mu \mathrm{m})$.

Table 1. Experimental parameters. S—spark plasma sintering (SPS); G—gas pressure sintering (GPS); $\mathrm{CA}-\mathrm{CeO}_{2}-\mathrm{Al}_{2} \mathrm{O}_{3} ; \mathrm{YA}-\mathrm{Yb}_{2} \mathrm{O}_{3}-\mathrm{Al}_{2} \mathrm{O}_{3}$.

\begin{tabular}{cccccc}
\hline Samples & $\begin{array}{c}\text { Sintering Conditions } \\
\text { Sintering Technique/Sintering } \\
\text { Temperature/Holding Time }\end{array}$ & $\begin{array}{c}\mathbf{Y b}_{\mathbf{2}} \mathbf{O}_{3} \\
\mathbf{( w t . \% )}\end{array}$ & $\begin{array}{c}\mathbf{C e O}_{\mathbf{2}} \\
\mathbf{( w t . \% )}\end{array}$ & $\begin{array}{c}\mathbf{A l}_{\mathbf{2}} \mathbf{O}_{3} \\
\mathbf{( w t . \% )}\end{array}$ & $\begin{array}{c}\mathrm{Si}_{3} \mathbf{N}_{\mathbf{4}} \\
\mathbf{( w t .} \%)\end{array}$ \\
\hline SYA & SPS/1873 K/6 min & 5 & 0 & 2 & 93 \\
SCA & GPS/2053 K/60 min & 5 & 5 & 2 & 93 \\
\hline GYA & & 0 & 5 & 2 & 93 \\
GCA & & & & \\
\hline
\end{tabular}

For SPS, the powder mixture was loaded into a graphite mold and sintered at $1873 \mathrm{~K}$ for $6 \mathrm{~min}$ with a maximum applied pressure of $50 \mathrm{MPa}$. Similarly, for GPS, the samples were firstly dry-press molded, before being cold isostatic pressed at $200 \mathrm{MPa}$ for $3 \mathrm{~min}$, and finally sintered at $2053 \mathrm{~K}$ for $60 \mathrm{~min}$ with maximum applied nitrogen pressure of $6 \mathrm{MPa}$. After SPS and GPS sintering, the ceramic blocks were cut, ground, and polished for physical analysis and characterization. 


\subsection{Characterization}

The bulk density of the samples was measured in distilled water by the Archimedean displacement technique. The relative density was calculated by dividing the bulk density with theoretical density. The bending strength of the samples was determined by three-point bending. The samples with the size of $1.5 \mathrm{~mm} \times 1.5 \mathrm{~mm} \times 20 \mathrm{~mm}$ were prepared by grinding and polishing, and the tests were carried out on an Instron-5500 machine with a span width of $16 \mathrm{~mm}$ and a loading rate of $0.5 \mathrm{~mm} / \mathrm{min}$. A total of 10 samples were employed for the testing, and the average value was determined. The hardness was determined using a microhardness tester (Model: TUKON ${ }^{\mathrm{TM}}$ 2500, Wilson, New York, USA) on the polished surface of the samples with a load of $5 \mathrm{~kg}$ and dwell time of $15 \mathrm{~s}$. The indentation fracture resistance was measured with a load of $20 \mathrm{~kg}$ using the same equipment and calculated according to the Shetty equation [16]. A total of 10 indentations were made on the surface of each sample for microhardness and fracture toughness testing. The phase composition was determined by X-ray diffraction (XRD; D8 ADVANCE A25 BRUKER, BRUKER, Karlsruhe, Germany) using Cu-K $\alpha$ radiation. A scanning electron microscope (SEM; S-4800, hitachi, Tokyo, Japan) was employed to observe the microstructure of fractured samples. The thermal conductivity of the samples was calculated by Equation (1) [17].

$$
\lambda=\rho \cdot C_{p} \cdot \alpha,
$$

where $\rho, \alpha$, and $C_{P}$ are the bulk density, thermal diffusivity, and heat capacity, respectively. Thermal diffusivity $(\alpha)$ was determined by the wave thermal analysis method (Model: ai-phase mobile 1, Japan) on relevant samples with a thickness of about $0.5 \mathrm{~mm}$, while a constant value of heat capacity, $680 \mathrm{~J} /(\mathrm{kg} \cdot \mathrm{K})$ was used for the calculations of thermal conductivity.

\section{Results and Discussion}

The specific sintering technique and particular additive combinations had characteristic effects on the performance of $\mathrm{Si}_{3} \mathrm{~N}_{4}$ ceramics, as discussed below.

\subsection{Relative Density}

The effect of sintering additive combinations and sintering techniques on the relative density of the sintered samples is shown in Table 2. Irrespective of the sintering additives, the density of SPS sintered samples was greater than that of GPS sintered samples, mainly because the higher pressure of $50 \mathrm{MPa}$ was applied in SPS sintering, which promoted densification [18]. Under the same sintering technique, the relative density of $\mathrm{CA}$ was slightly higher than that of $\mathrm{YA}$ because $\mathrm{CeO}_{2}$ can form a eutectic liquid phase $\left(\mathrm{CeO}_{2}-\mathrm{SiO}_{2} / \mathrm{CeO}_{2}-\mathrm{SiO}_{2}-\mathrm{Si}_{3} \mathrm{~N}_{4}\right)$ at lower temperatures than $\mathrm{Yb}_{2} \mathrm{O}_{3}[19,20]$. With the rise of temperature to respective sintering temperatures, the viscosity of the eutectic liquid phase further reduced, which effectively enhanced the rearrangement of silicon nitride granules and promoted densification.

Table 2. The observed density, $\beta$-phase percentage, and thermal conductivity of samples.

\begin{tabular}{|c|c|c|c|c|}
\hline Sample & $\beta /(\alpha+\beta)($ wt. $\%)$ & $\begin{array}{l}\text { Bulk Density } \\
\left(\mathrm{kg} / \mathrm{m}^{3}\right)\end{array}$ & $\begin{array}{c}\text { Relative Density } \\
\text { (\%) }\end{array}$ & $\begin{array}{l}\text { Thermal Conductivity } \\
(\mathrm{W} /(\mathrm{m} \cdot \mathrm{K}))\end{array}$ \\
\hline SYA & 91.43 & 3310 & 99.6 & 49 \\
\hline SCA & 93.25 & 3370 & 99.7 & 38 \\
\hline GYA & 99.58 & 3290 & 99.2 & 42 \\
\hline GCA & 99.61 & 3350 & 99.3 & 35 \\
\hline
\end{tabular}

\subsection{Phase Composition}

The XRD profile patterns of the sintered samples are presented in Figure 1. It can be observed that different sintering techniques and additive combinations had dissimilar effects on the phase composition of the samples. The main crystalline phase in all the samples was $\beta-\mathrm{Si}_{3} \mathrm{~N}_{4}$. The XRD 
patterns of SPS sintered samples in comparison to GPS sintered samples showed some peaks of $\alpha-\mathrm{Si}_{3} \mathrm{~N}_{4}$, indicating that the transformation of $\alpha-\mathrm{Si}_{3} \mathrm{~N}_{4}$ to $\beta-\mathrm{Si}_{3} \mathrm{~N}_{4}$ in SPS sintering was not entirely completed. SPS sintering is a rapid sintering process and, therefore, time may not be sufficient for the complete phase transformation of $\alpha-\mathrm{Si}_{3} \mathrm{~N}_{4}$ to $\beta-\mathrm{Si}_{3} \mathrm{~N}_{4}$. However, in the case of GPS sintered samples, the phase transformation from $\alpha-\mathrm{Si}_{3} \mathrm{~N}_{4}$ to $\beta-\mathrm{Si}_{3} \mathrm{~N}_{4}$ was almost entirely completed because of the higher sintering temperature and prolonged heat preservation time.

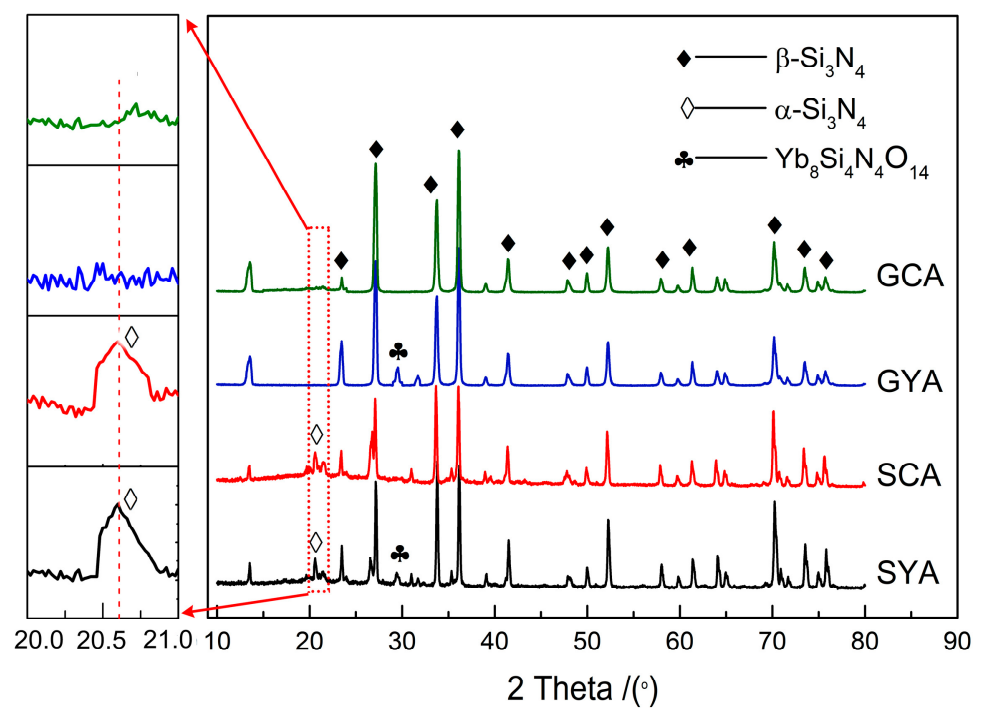

Figure 1. X-ray diffraction (XRD) patterns of the samples obtained by SYA, SCA, GYA, and GCA, where $\mathrm{S}$ represents spark plasma sintering (SPS), $\mathrm{G}$ represents gas pressure sintering (GPS), CA represents $\mathrm{CeO}_{2}-\mathrm{Al}_{2} \mathrm{O}_{3}$, and $\mathrm{YA}$ represents $\mathrm{Yb}_{2} \mathrm{O}_{3}-\mathrm{Al}_{2} \mathrm{O}_{3}$.

In the samples sintered with the $\mathrm{Yb}_{2} \mathrm{O}_{3}-\mathrm{Al}_{2} \mathrm{O}_{3}$ additive combination, some peaks of crystalline grain boundary phase $\mathrm{Yb}_{8} \mathrm{Si}_{4} \mathrm{~N}_{4} \mathrm{O}_{14}$ were detected, which could have formed upon cooling of the eutectic liquid produced by the reaction of $\mathrm{Yb}_{2} \mathrm{O}_{3}$ with $\mathrm{SiO}_{2}$ on the surface of $\mathrm{Si}_{3} \mathrm{~N}_{4}$ and $\mathrm{Si}_{3} \mathrm{~N}_{4}$ itself. The intensity of this phase increased with the rise of sintering temperature to $2073 \mathrm{~K}$ in GPS. The characteristic feature of $\mathrm{Yb}_{2} \mathrm{O}_{3}$ forming a crystalline grain boundary phase was already reported by researchers [10].

\subsection{Phase Transition Rate}

The schematic sequence of $\mathrm{Si}_{3} \mathrm{~N}_{4}$ crystal phase transition is shown in Figure 2. With the formation of the liquid phase by the reaction of sintering additives with $\mathrm{SiO}_{2}$ on the surface of $\mathrm{Si}_{3} \mathrm{~N}_{4}$ and partly $\mathrm{Si}_{3} \mathrm{~N}_{4}$ itself, the $\alpha-\mathrm{Si}_{3} \mathrm{~N}_{4}$, being an unstable phase, dissolved in the liquid phase and re-precipitated in the form of elongated $\beta-\mathrm{Si}_{3} \mathrm{~N}_{4}$ needles. The initial $\beta$-phase seeds provide nucleation sites or promote the re-precipitation process. The aspect ratio of newly produced or re-precipitated $\beta$-phase depends on the sintering parameters, sintering additives, the viscosity of liquid phase, etc. 


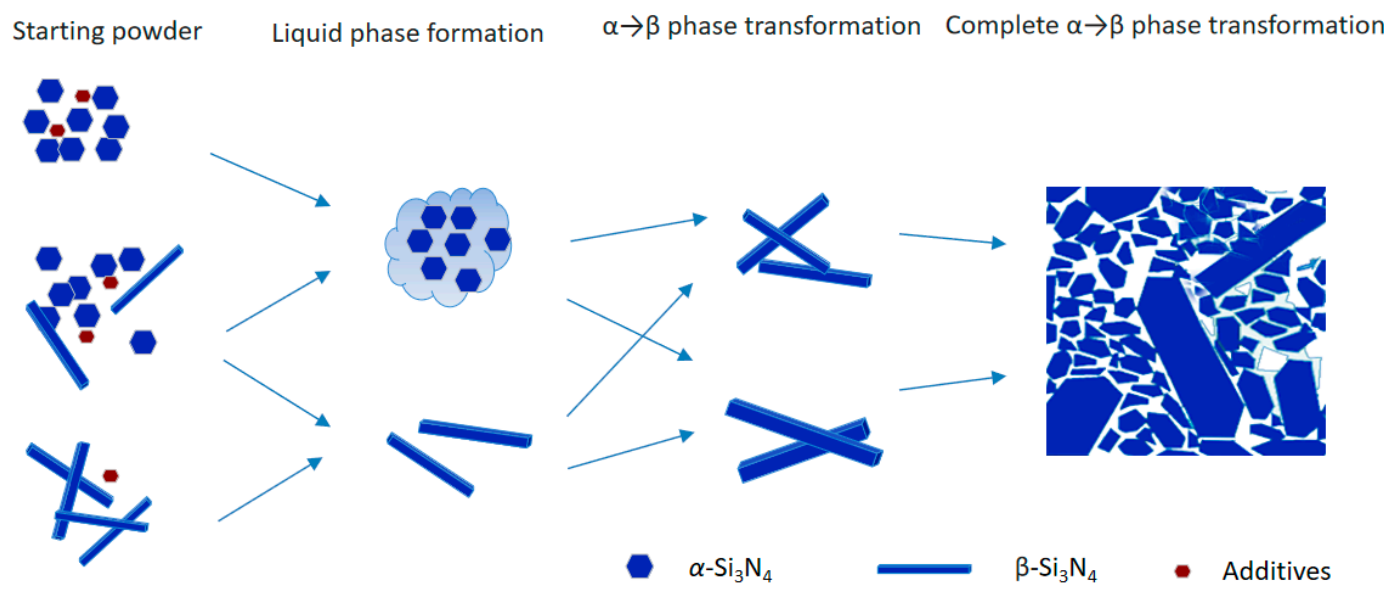

Figure 2. The schematic representation of $\mathrm{Si}_{3} \mathrm{~N}_{4}$ crystal phase transition.

The phase content of $\beta-\mathrm{Si}_{3} \mathrm{~N}_{4}$ was determined by the calculation method proposed by Gazzara and Messier [21], as shown in Equation (2).

$$
\beta-\mathrm{Si}_{3} \mathrm{~N}_{4}(w \mathrm{t} \%)=\frac{\mathrm{I}_{\beta(101)}+\mathrm{I}_{\beta(210)}}{\left[\mathrm{I}_{\alpha(102)}+\mathrm{I}_{\alpha(210)}+\mathrm{I}_{\beta(101)}+\mathrm{I}_{\beta(210)}\right]},
$$

where $\mathrm{I}_{\beta(101)}$ and $\mathrm{I}_{\beta(210)}$ are the diffraction intensities of the (101) and (210) planes of $\beta-\mathrm{Si}_{3} \mathrm{~N}_{4}$, and $\mathrm{I}_{\alpha(102)}$ and $\mathrm{I}_{\alpha(201)}$ represent the intensities of the (102) and (201) planes of $\alpha-\mathrm{Si}_{3} \mathrm{~N}_{4}$.

For both additive combinations, the phase transition rate, $\alpha-\mathrm{Si}_{3} \mathrm{~N}_{4}$ to $\beta-\mathrm{Si}_{3} \mathrm{~N}_{4}$, for GPS was higher than for SPS, as shown in Table 2. The sintering temperature of GPS was higher, and the holding time at the sintering temperature was also more than one hour compared to the lower sintering temperature and shorter holding time (15 $\mathrm{min}$ ) in SPS sintering. Therefore, the higher sintering temperature and prolonged holding time might have facilitated the higher phase transition in GPS.

The variation in phase transition rates of YA and CA additive combinations in GPS sintering was not noticeable, and both were close to $99.6 \%$. However, SPS sintering had a small difference in which the phase transition rate of CA was slightly higher than that of YA. The reason may be the lower eutectic liquid formation temperature (1723 K) [22] with $\mathrm{CeO}_{2}$ via the $\mathrm{CeO}_{2}-\mathrm{SiO}_{2}-\mathrm{Si}_{3} \mathrm{~N}_{4}$ reaction, which offers more time for $\alpha-\mathrm{Si}_{3} \mathrm{~N}_{4}$ dissolution in the eutectic liquid phase.

\subsection{Microstructure}

SEM micrographs of the fractured surfaces of SYA, SCA, GYA, and GCA samples are shown in Figure 3. The microstructures were mainly dominated by the long cylindrical $\beta$-phase. Pores were almost entirely excluded, ensuring densification of the $\mathrm{Si}_{3} \mathrm{~N}_{4}$ samples. From Figure $3 \mathrm{a}, \mathrm{b}$, it can be seen that the microstructure of samples sintered with SPS sintering was fine. The thickness of the elongated $\beta$-grains was small, and the grains were tightly interconnected in comparison to GPS sintered samples (Figure 3c,d), which comprised a coarse microstructure. Similarly, the samples sintered with the YA additive combination (Figure $3 a, c)$ contained comparatively less of an intergranular phase than the samples with the CA additive combination (Figure $3 b, d$ ). 


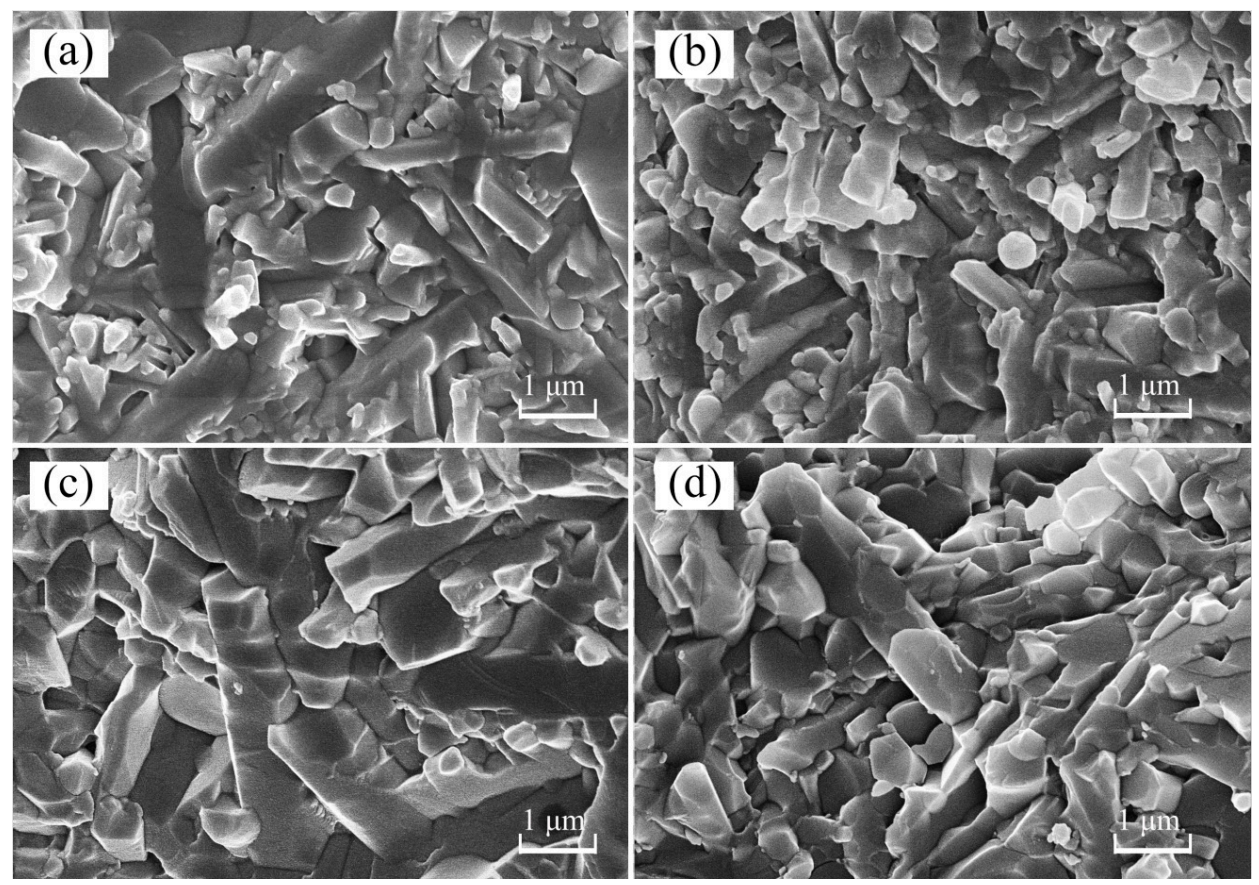

Figure 3. SEM micrographs of the fractured surfaces of $\mathrm{Si}_{3} \mathrm{~N}_{4}$ samples: (a) SYA; (b) SCA; (c) GYA; (d) GCA.

\subsection{Mechanical Properties}

\subsubsection{Bending Strength}

The bending strength of the $\mathrm{Si}_{3} \mathrm{~N}_{4}$ samples is shown in Figure 4. The bending strength values of SPS sintered samples were higher than those of GPS sintered samples. The bending strength values of the SYA and SCA samples were $1013 \mathrm{MPa}$ and $954 \mathrm{MPa}$, respectively; however, with GPS sintering, the corresponding values were only $915 \mathrm{MPa}$ (GYA) and $887 \mathrm{MPa}$ (GCA). The fine microstructure with uniform distribution of elongated $\beta$-grains, as shown in Figure $3 a, b$, resulted in higher bending strength values in SPS sintered samples.

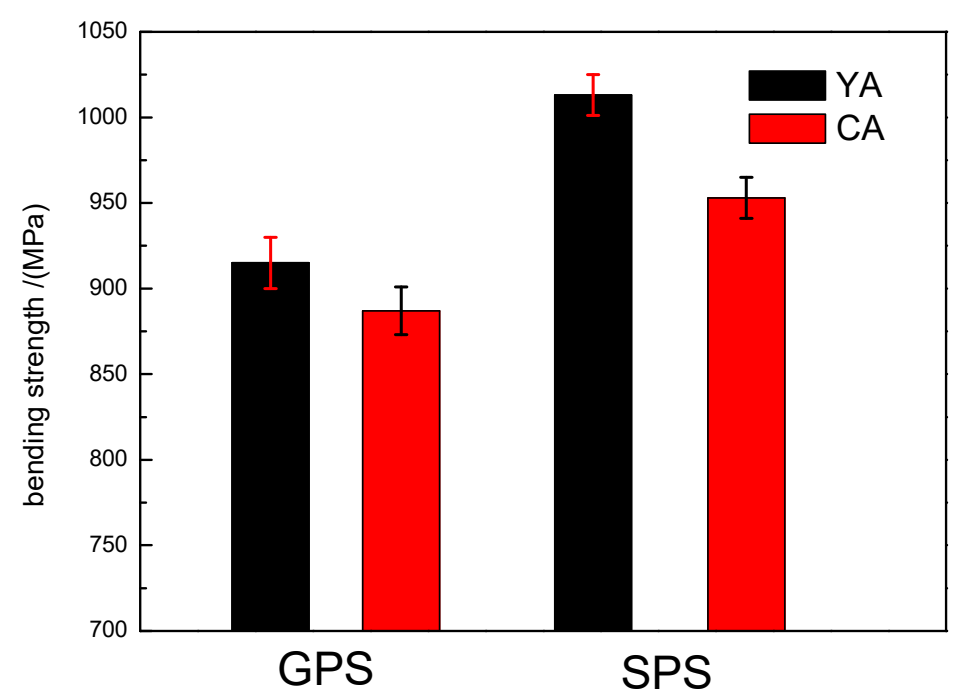

Figure 4. Bending strength (MPa) of GPS and SPS sintered silicon nitride samples.

The bending strength of samples sintered with the YA additive was greater than that with CA in both GPS and SPS sintering. According to the calculation method proposed by Tseng shown in 
Equation (3) [23], the bending strength depends on the average length-to-diameter ratio, called the aspect ratio (AR), of $\beta-\mathrm{Si}_{3} \mathrm{~N}_{4}$ grains. It can be observed from Figure $3 \mathrm{a}, \mathrm{c}$ that the aspect ratio of $\beta-\mathrm{Si}_{3} \mathrm{~N}_{4}$ grains with the YA additive combination was higher than that with $C A$, indicating that $Y A$ is more useful to promote the bending strength than CA.

$$
\mathrm{AR}=\frac{\mathrm{L}}{\mathrm{W}}=\left(\frac{\mathrm{K}_{\mathrm{L}}^{1 / 3}}{\mathrm{~K}_{\mathrm{W}}^{1 / 5}}\right) \times \mathrm{t}^{2 / 15} \exp \left[\frac{\left(\frac{\mathrm{Q}_{\mathrm{L}}}{3}-\frac{\mathrm{Q}_{\mathrm{W}}}{5}\right)}{\mathrm{kT}}\right]
$$

where $A R$ is the aspect ratio, $K_{L}$ and $K_{W}$ are the growth rate constants of $\beta-\mathrm{Si}_{3} \mathrm{~N}_{4}$ in length and width, respectively, $Q_{\mathrm{L}}$ and $\mathrm{Q}_{\mathrm{W}}$ are the respective activation energies $\left(\mathrm{Q}_{\mathrm{L}}=686 \mathrm{~J} / \mathrm{mol}, \mathrm{Q}_{\mathrm{W}}=772 \mathrm{~J} / \mathrm{mol}\right), \mathrm{k}$ is the gas constant, $\mathrm{t}$ is the time, and $\mathrm{T}$ is the absolute temperature.

\subsubsection{Hardness}

The hardness values of the sintered silicon nitride samples are shown in Figure 5. The hardness of ceramic materials depends on the bonding type, crystal structure, and chemical composition. In addition, the microstructure, cracks, and impurities of ceramic materials have an influence on the hardness.

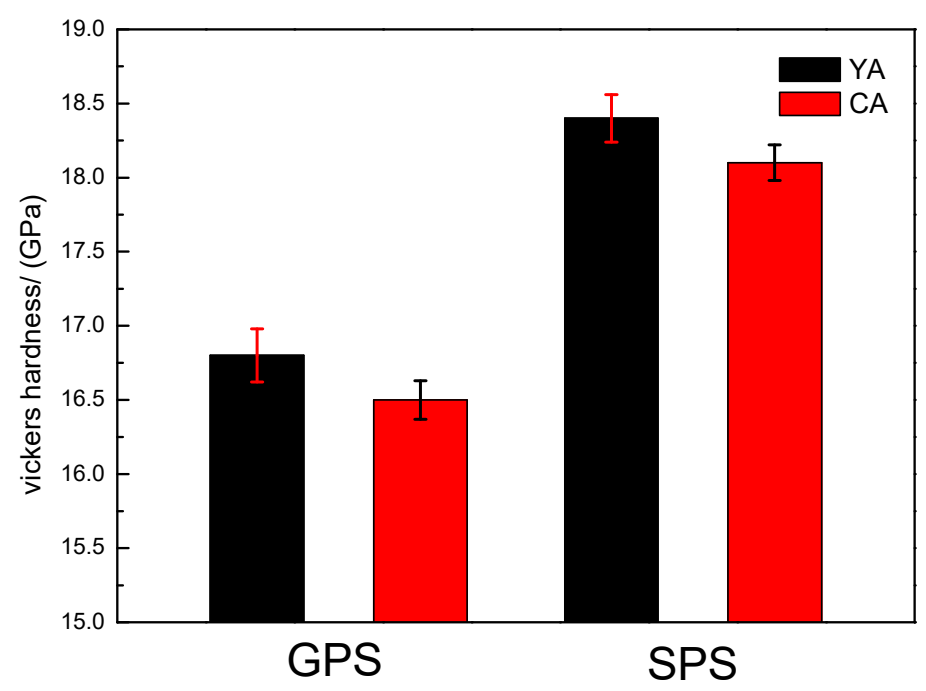

Figure 5. Micro Vickers hardness (GPa) of GPS and SPS sintered silicon nitride samples.

The hardness of the samples sintered with the YA additive combination was higher than that with CA. Xie [24] illustrated that smaller-radii rare-earth ions offer higher scratch and penetration resistance and, accordingly, demonstrate higher hardness. The atomic radius of Ce is greater than that of $\mathrm{Yb}$; therefore, conversely, the hardness of the samples with the $\mathrm{YA}$ additive combination is greater than that of CA. Research proved [25] that the hardness of sintered $\mathrm{Si}_{3} \mathrm{~N}_{4}$ depends on the content of $\alpha-\mathrm{Si}_{3} \mathrm{~N}_{4}$, density, and characteristics of the intergranular glassy phase. Therefore, a higher content of $\alpha-\mathrm{Si}_{3} \mathrm{~N}_{4}$, high density, and large glass hardness are beneficial for improving the hardness of $\mathrm{Si}_{3} \mathrm{~N}_{4}$. From Table 2, it can be seen that the content of $\alpha-\mathrm{Si}_{3} \mathrm{~N}_{4}$ phase in the samples which were sintered by SPS was more substantial than those sintered by GPS. The samples sintered by GPS (Table 2) were composed almost entirely of the $\beta-\mathrm{Si}_{3} \mathrm{~N}_{4}$ phase without $\alpha-\mathrm{Si}_{3} \mathrm{~N}_{4}$ and a small amount of crystalline phase $\mathrm{Yb}_{8} \mathrm{Si}_{4} \mathrm{~N}_{4} \mathrm{O}_{14}$. Moreover, the relative density of the silicon nitride samples with SPS was greater than that of the samples with GPS. Therefore, the hardness after SPS sintering was greater than GPS sintering, which is consistent with the plot shown in Figure 5. 


\subsubsection{Fracture Toughness}

The fracture toughness of GPS and SPS sintered samples with YA and CA additive combinations is shown in Figure 6.

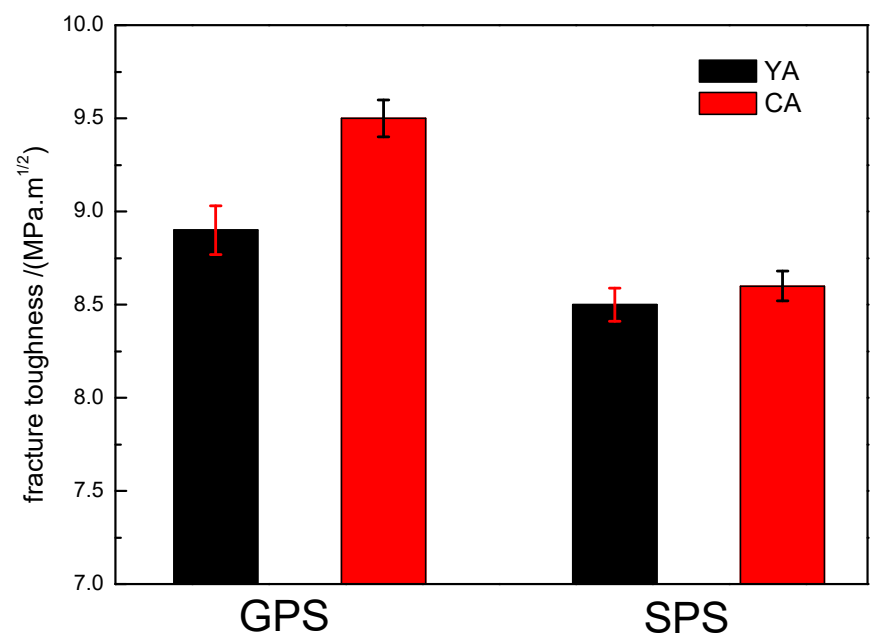

Figure 6. Fracture toughness $\left(\mathrm{MPa} \cdot \mathrm{m}^{1 / 2}\right)$ of GPS and SPS sintered silicon nitride samples.

It can be seen that the fracture toughness values of the SPS sintered samples were greater than those of GPS sintered samples. With the YA and CA additive combinations, the values by SPS sintering were $9.5 \mathrm{MPa} \cdot \mathrm{m}^{1 / 2}$ and $8.6 \mathrm{MPa} \cdot \mathrm{m}^{1 / 2}$, respectively; however, the corresponding values by GPS sintering were $8.9 \mathrm{MPa} \cdot \mathrm{m}^{1 / 2}$ and $8.5 \mathrm{MPa} \cdot \mathrm{m}^{1 / 2}$, respectively. Fracture toughness was observed to enhance when large elongated grains are formed in a fine matrix [26]. Therefore, the fine microstructure in SPS sintered samples (Figure 3a,b) improved the fracture toughness.

Similarly, the fracture toughness of samples with the YA additive was greater than that with CA in SPS and GPS sintering, indicating that the YA system can promote fracture toughness more than the CA system.

Fracture mode has an influence on the fracture toughness. The long columnar $\beta-\mathrm{Si}_{3} \mathrm{~N}_{4}$ grains in the sintered $\mathrm{Si}_{3} \mathrm{~N}_{4}$ ceramics influence the crack propagation path. It means that the crack propagation takes on more tortuous paths, which consume extra fracture energy. Therefore, in order to find the crack propagation behavior and toughening mechanism of $\mathrm{Si}_{3} \mathrm{~N}_{4}$ ceramic at room temperature, the crack propagation paths of GPS sintered samples with the YA and CA additive systems were observed under the scanning electron microscope. The microscopic appearance of the fractured samples is shown in Figure 7; it can be assumed that crack propagation in the CA additive system mainly adopted a transgranular mode, while that with YA mainly focused on the intergranular mode of fracture.

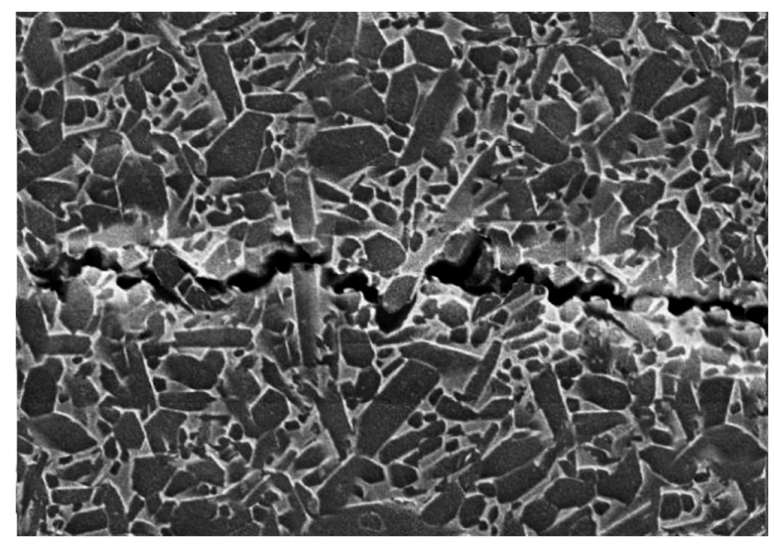

Figure 7. GCA crack propagation micromorphology. 
The specific interlocking microstructure can effectively improve the fracture toughness of $\mathrm{Si}_{3} \mathrm{~N}_{4}$ ceramic via the elongated $\beta-\mathrm{Si}_{3} \mathrm{~N}_{4}$ grains, due to crack deflection and crack bridging.

The $\mathrm{Si}_{3} \mathrm{~N}_{4}$ ceramics belong to the class of hard brittle materials. The toughening method is mainly through crack bridging and deflection by elongated $\beta$ grains and the toughening behavior of the grain pulling effect. On the one hand, the crack path along the grains induces the propagation of the crack with more twists and turns. On the other hand, $\mathrm{Si}_{3} \mathrm{~N}_{4}$ ceramics produce more bifurcation, crack deflection, and a toughening effect. For instance, grain pulling is the main cause of the increase in fracture toughness.

Murgatroyd et al. [27] believes that there are some elastic regions in the glass that contain small areas of quasi-viscous material. According to Marsh et al. [28], glass is not a pure brittle material, but is treated as an elastic-plastic complex. However, more experiments are required to verify these claims.

\subsection{Thermal Conductivity}

The thermal conductivity with the YA additive was higher than that with CA as shown in Table 2. The possible explanation can be given by the formula derived by Morikawa [24,29].

$$
\lg \lambda=\left(\lg \lambda_{m}-C_{f} \lg \lambda_{f}\right) V+C_{f} \lg \lambda_{f}
$$

where $\lambda$ is the net thermal conductivity of $\mathrm{Si}_{3} \mathrm{~N}_{4}$ ceramic, while $\lambda_{m}$ and $\lambda_{f}$ are representations of the thermal conductivities of intergranular or intercrystalline phase and $\beta-\mathrm{Si}_{3} \mathrm{~N}_{4}$ columnar crystals, respectively. $C_{f}$ is the thermal resistance effect and $V$ is the intercrystalline volume fraction. Therefore, the thermal conductivity of silicon nitride ceramics, i.e., $\lg \lambda$, is proportional to the intercrystalline phase volume fraction $V$.

Related reports [30] about the sintering processing of AlN ceramic elaborated that, in the presence of a carbon and nitrogen atmosphere, $\mathrm{Y}-\mathrm{Al}$ - meets composite oxide from inside the base, and runs to the substrate surface to generate $\mathrm{YN}$ and AlN, resulting in AlN lattice purification, thereby improving the thermal conductivity of AlN substrate. A similar situation may explain that the experiment with intercrystalline $\mathrm{Yb}_{8} \mathrm{Si}_{4} \mathrm{~N}_{4} \mathrm{O}_{14}$ may partly be broken down into $\mathrm{Yb}_{2} \mathrm{O}_{3}$ and $\mathrm{Si}_{3} \mathrm{~N}_{4}$, and, under the effect of the concentration gradient diffusion, it may transfer gradually to the sample surface, thereby reducing the content of intergranular phase. The thermal conductivity of YA was greater than CA in the SPS or GPS sintering method.

According to Equation (5) by Slack [31], the average atomic weight of the $\beta-\mathrm{Si}_{3} \mathrm{~N}_{4}$ strong atomic bond and non-harmonic vibration of the crystal are similar to SiC and AlN. Therefore, the content of $\beta-\mathrm{Si}_{3} \mathrm{~N}_{4}$ is proportional to its thermal conductivity, and it has some influence on grain boundary, grain, and so on. Therefore, the thermal conductivity of GPS sintering samples is higher than that of SPS.

$$
\mathrm{k}=\frac{\mathrm{B} \bar{M} \delta^{3} \Theta_{D}}{T \gamma^{2}}
$$

where $\bar{M}$ is the mean atomic weight, $\delta$ is the cube root of the atomic volume of a unit, $\gamma$ is the Gruneisen constant, $\Theta_{D}$ is the Debye temperature, and B is a constant.

High-thermal-conductivity ceramics should have the following conditions: (1) small average atomic weight; (2) high atomic bonding strength; (3) relatively simple crystal structure; and (4) low lattice anharmonic vibration. However, the thermal conductivity of silicon nitride was not high in this experiment, due to its complicated structure, which has a significant relationship with the scattering of phonons.

\section{Conclusions}

The dense and uniform $\mathrm{Si}_{3} \mathrm{~N}_{4}$ ceramics were prepared by GPS and SPS using $5 \mathrm{wt.} \% \mathrm{Yb}_{2} \mathrm{O}_{3}-2$ wt. $\% \mathrm{Al}_{2} \mathrm{O}_{3}$ and 5 wt. $\% \mathrm{CeO}_{2}-2$ wt. $\% \mathrm{Al}_{2} \mathrm{O}_{3}$ additive systems. The relative density, phase composition, 
phase transition rate, mechanical properties, and thermal conductivity were comparatively studied based on the sintering techniques and additive systems. The results are summarized below.

For GPS, the bending strength, hardness, and thermal conductivity of the YA system were higher than that of the CA system, while the fracture toughness and phase transformation rate were lower. Furthermore, the highest value of fracture toughness $\left(9.5 \mathrm{MPa} \cdot \mathrm{m}^{1 / 2}\right)$ was also obtained in the case of the CA additive system. For SPS, the highest values of bending strength (1013 MPa), Vickers hardness $(18.4 \mathrm{GPa})$, and thermal conductivity $(49 \mathrm{~W} /(\mathrm{m} \cdot \mathrm{K}))$ were obtained in the case of the YA additive system; conversely, the relative density, phase transition rate, and the fracture toughness of the CA additive system were greater than that with YA. However, irrespective of the employed additive systems, the relative density, thermal conductivity, bending strength, and Vickers hardness of the SPS sintered samples were higher than those of the GPS sintered samples.

Further research studies will mainly focus on investigating the sintering mechanism, with impurity phase reduction, and a detailed chemical analysis of sintered $\mathrm{Si}_{3} \mathrm{~N}_{4}$ ceramics.

Author Contributions: L.Y. conceived the idea, made experimentation plan and performed data interpretaion; A.D. contributed to the conception of study and wrote the manuscript; B.F. performed the testing and carried out calculations; Y.Z. and Z.X. carried out data analysis and revised the manuscript.

Funding: This research was funded by the National Key Research and Development Program of China grant number No. 2017YFB0310400. And the APC was funded by the National Key Research and Development Program of China.

Acknowledgments: The authors gratefully acknowledge the financial support from the National Key Research and Development Program of China under Grant No. 2017YFB0310400.

Conflicts of Interest: The authors declare no conflicts of interest.

\section{References}

1. Wu, T.L.; Marcon, D.; Ronchi, N.; Bakeroot, B.; You, S.Z.; Stoffels, S.; Hove, M.V.; Bisi, D.; Meneghini, M.; Groeseneken, G.; et al. Analysis of slow de-trapping phenomena after a positive gate bias on AlGaN/GaN MIS-HEMTs with in-situ $\mathrm{Si}_{3} \mathrm{~N}_{4} / \mathrm{Al}_{2} \mathrm{O}_{3}$ bilayer gate dielectrics. Solid State Electron. 2015, 103, 127-130. [CrossRef]

2. Kumar, A.; Gokhale, A.; Ghosh, S.; Aravindan, S. Effect of nano-sized sintering additives on microstructure and mechanical properties of $\mathrm{Si}_{3} \mathrm{~N}_{4}$ ceramics. Mater. Sci. Eng. A 2019, 750, 132-140. [CrossRef]

3. Yu, F.L.; Bai, Y.; Du, J.; Yu, P.P.; Wang, J.Z.; Yang, J.F. Study on the Preparation, Properties and Mechnism of $\beta-\mathrm{Si}_{3} \mathrm{~N}_{4}$ Crystal Seeds. J. Synth. Cryst. 2011, 40, 1595-1601.

4. Yue, C.S.; Peng, B.; Guo, M.; Zhang, M. Study on Inducing Synthesis and Growth Mechanism of $\beta$-SiAlON Whisker. J. Synth. Cryst. 2011, 40, 1181-1187.

5. Zou, C.R.; Zhang, C.R.; Li, B.; Wang, S.Q.; Cao, F. Microstructure and properties of porous silicon nitride ceramics prepared by gel-casting and gas pressure sintering. Mater. Des. 2013, 44, 114-118. [CrossRef]

6. Nishimura, T.; Mitomo, M.; Suematsu, H. High temperature strength of silicon nitride ceramics with ytterbium silicon oxynitride. J. Mater. Res. 1997, 12, 203-209. [CrossRef]

7. Lu, H.H.; Huang, J.L. Effect of $\mathrm{Y}_{2} \mathrm{O}_{3}$ and $\mathrm{Yb}_{2} \mathrm{O}_{3}$ on the microstructure and mechanical properties of silicon nitride. Ceram. Int. 2001, 27, 621-628. [CrossRef]

8. Tian, X.H.; Zhao, J.; Lei, S.T.; Yang, H.F.; Wang, Z.B. High temperature mechanical properties of $\mathrm{Si}_{3} \mathrm{~N}_{4} /(\mathrm{W}$, Ti)C graded nano-composite ceramic tool material. Ceram. Int. 2018, 44, 7128-7133. [CrossRef]

9. Kondo, N.; Suzuki, Y.; Miyajima, T.; Ohji, T. High temperature mechanical properties of sinter-forged silicon nitride with ytterbia additive. J. Eur. Ceram. Soc. 2003, 23, 809-815. [CrossRef]

10. Vetrano, J.S.; Kleebe, H.J.; Hampp, E.; Hoffmann, M.J.; Rühle, M.; Cannon, R.M. $\mathrm{Yb}_{2} \mathrm{O}_{3}$-fluxed sintered silicon nitride. J. Mater. Sci. 1993, 28, 3529-3538. [CrossRef]

11. Yang, J.F.; Ohji, T.; Kanzaki, S.; Díaz, A.; Hampshire, S. Microstructure and Mechanical Properties of Silicon Nitride Ceramics with Controlled Porosity. J. Am. Ceram. Soc. 2002, 85, 1512-1516. [CrossRef]

12. Han, W.B.; Li, Y.X.; Chen, G.Q.; Yang, Q. Effect of sintering additive composition on microstructure and mechanical properties of silicon nitride. Mater. Sci. Eng. A 2017, 700, 19-24. [CrossRef] 
13. Liu, T.T.; Jiang, C.; Wei, G.U.O. Effect of $\mathrm{CeO}_{2}$ on low temperature pressureless sintering of porous $\mathrm{Si}_{3} \mathrm{~N}_{4}$ ceramics. J. Rare Earths 2017, 35, 172-176. [CrossRef]

14. Lukianova, O.A.; Ivanov, O.N. The effect of $\mathrm{Al}_{2} \mathrm{O}_{3}-\mathrm{MgO}$ additives on the microstructure of spark plasma sintered silicon nitride. Ceram. Int. 2018, 44, 390-393. [CrossRef]

15. Yang, L.L.; Xie, Z.P.; Song, M. Effect of $\mathrm{Yb}_{2} \mathrm{O}_{3}-\mathrm{Al}_{2} \mathrm{O}_{3}$ Sintering Aids on the Properties of Silicon Nitride Ceramics Prepared by Gas Pressure Sintering. J. Synth. Cryst. 2015, 44, 2503-2509.

16. Shetty, D.K.; Wright, I.G.; Mincer, P.N.; Clauser, A.H. Indentation fracture of WC-Co cermets. J. Mater. Sci. 1985, 20, 1873-1882. [CrossRef]

17. Matović, B.; Bošković, S. Thermal conductivity of pressureless sintered $\mathrm{Si}_{3} \mathrm{~N}_{4}$ ceramics with Li-exchanged zeolite. J. Serbian Chem. Soc. 2004, 69, 705-710. [CrossRef]

18. Yang, L.L.; Xie, Z.P.; Li, S. Effect of Multi-Sintering Additive $\mathrm{MgO}-\mathrm{Al}_{2} \mathrm{O}_{3}-\mathrm{CeO}_{2}$ on Densification and Properties of Silicon Nitride Ceramics by Spark Plasma Sintering. J. Chin. Ceram. Soc. 2015, 43, 1712-1718.

19. Yang, J.F.; Deng, Z.Y.; Ohji, T. Fabrication and characterisation of porous silicon nitride ceramics using $\mathrm{Yb}_{2} \mathrm{O}_{3}$ as sintering additive. J. Eur. Ceram. Soc. 2003, 23, 371-378. [CrossRef]

20. Li, Y.X.; Han, W.B.; Chen, G.Q.; An, J.D. Influence of $\mathrm{CeO}_{2}$ addition on $\mathrm{Si}_{3} \mathrm{~N}_{4}$ ceramics. Mater. Res. Innov. 2015, 19, 339-342. [CrossRef]

21. Kawai, C.; Yamakawa, A. Effect of porosity and microstructure on the strength of $\mathrm{Si}_{3} \mathrm{~N}_{4}$ : Designed microstructure for high strength, high thermal shock resistance, and facile machining. J. Am. Ceram. Soc. 1997, 80, 2705-2708. [CrossRef]

22. Zhu, X.W.; Zhou, Y.; Hirao, K.; Ishigaki, T.; Sakka, Y. Potential use of only $\mathrm{Yb}_{2} \mathrm{O}_{3}$ in producing dense $\mathrm{Si}_{3} \mathrm{~N}_{4}$ ceramics with high thermal conductivity by gas pressure sintering. Sci. Technol. Adv. Mater. 2010, 11, 1-11. [CrossRef]

23. Tseng, T.Y. Use of Phase Diagrams in the Study of Silicon Nitride Ceramics. In Phase Diagrams in Advanced Ceramics; Elsevier: Amsterdam, The Netherlands, 1995; pp. 127-156.

24. Xie, Z.P. Structural Ceramics; Tsinghua University Press: Beijing, China, 2011.

25. Charoo, M.S.; Wani, M.F. Friction and wear properties of nano- $\mathrm{Si}_{3} \mathrm{~N}_{4} /$ nano-SiC composite under nanolubricated conditions. J. Adv. Ceram. 2016, 5, 145-152. [CrossRef]

26. Xue, W.J.; Yi, J.; Xie, Z.P.; Liu, W.; Chen, J. Enhanced fracture toughness of silicon nitride ceramics. Script. Mater. 2012, 66, 891-894. [CrossRef]

27. Murgatroyd, J.B. Mechanism of brittle rupture. Nature 1944, 3897, 51-52. [CrossRef]

28. Marsh, D.M. Plastic flow and fracture of glass. Proc. R. Soc. Lond. Ser. A Math. Phys. Sci. 1964, 282, $33-43$.

29. Morikawa, J.; Hashimoto, T. New technique for fourier transform thermal analysis. J. Therm. Anal. Calorim. 2001, 64, 403-412. [CrossRef]

30. Lee, H.M.; Bharathi, K.; Kim, D.K. Processing and Characterization of Aluminum Nitride Ceramics for High Thermal Conductivity. Adv. Eng. Mater. 2014, 16, 655-669. [CrossRef]

31. Slack, G.A. Nonmetallic crystals with high thermal conductivity. J. Phys. Chem. Solids 1973, 34, $321-335$. [CrossRef]

(C) 2019 by the authors. Licensee MDPI, Basel, Switzerland. This article is an open access article distributed under the terms and conditions of the Creative Commons Attribution (CC BY) license (http://creativecommons.org/licenses/by/4.0/). 